\title{
A PRÁTICA DA INTERDIÇÃO: UM DESAFIO PARA A EFICÁCIA DA LEI BRASILEIRA DE INCLUSÃO
}

\author{
Iara Pereira Ribeiro* \\ Pedro do Amaral Fernando Ruiz ${ }^{* *}$
}

SUMÁRIO: Introdução; 2 Capacidade civil e o regime das incapacidades; 30 método de consulta aos registros de interdição; 3.1 Os grupos de classificação das interdições; 4 Resultados; 4.1 A idade dos interditados e eventuais implicações 5 Conclusões; Referências.

RESUMO: O artigo apresenta o resultado de pesquisa descritiva-quantitativa que se propôs a verificar se existe uma cultura da interdição no Brasil; para tanto realizou-se pesquisa empírica dos registros de interdição no $1^{\circ}$ Cartório de Registro Civil da cidade de Ribeirão Preto (SP), a fim de conhecer: a) quantidade de interdições realizadas; b) modalidade dessas interdições; c) média de idade dos interditados; d) motivo das interdições. A análise dos documentos apontou que os mandados de inscrição do registro de interdição não informam corretamente a motivação da sentença, o que impossibilita estabelecer os motivos e os limites da interdição. Tal prática atinge a autonomia da pessoa com deficiência, pois o não conhecimento público da natureza da deficiência cerceia a sua vontade para demais atos em que estaria plenamente apta, violando o direito à inclusão da pessoa com deficiência.

PALAVRAS-CHAVE: Pessoa com deficiência; Interdição; Pesquisa empírica.

\section{THE PRACTICE OF INTERDICTION: A CHALLENGE FOR THE EFFI- CACY OF INCLUSION IN BRAZILIAN LAW}

ABSTRACT: Current descriptive and quantitative research verifies the existence of an interdiction culture in Brazil. A research on interdiction registers retrieved from the First Notary Office of Civil Registration in Riberão Preto SP Brazil has been undertaken to tally a) the number of interdictions; b) their modality; c) average age of interdicted people; d) motives of interdiction. The documents revealed that interdiction registers failed to inform precisely the sentences' motivation and thus the establishment of the interdictions' motives and limits becomes impossible. The practice reaches the autonomy of the person with deficiency, since the public

\footnotetext{
"Docente de Direito Civil do Departamento de Direito Civil e Processo Civil da Faculdade de Direito de Ribeirão Preto da Universidade de São Paulo, Brasil. E-mail: iararibeiro@usp.br

${ }^{* *}$ Discente na Universidade de São Paulo - Faculdade de Direito de Ribeirão Preto, Brasil.
} 
non-acknowledgement of the deficiency impairs other acts in which it is wholly able. This violates the right of inclusion of the person with deficiency.

KEY WORDS: People with deficiency; Interdiction; empirical research.

\section{LA PRÁCTICA DE LA INTERDICCIÓN: UN DESAFÍO A LA EFICACIA DE LA LEY BRASILEÑA DE INCLUSIÓN}

RESUMEN: En el artículo se presenta el resultado de investigación descriptiva-cuantitativa que se propone a verificar si hay una cultura de la interdicción el Brasil; para tanto se realizó investigación empírica de los registros de interdicción en la $1^{a}$ Oficina de Registro Civil de la ciudad de Ribeirão Preto, SP, con la finalidad de conocer: a) cantidad de interdicciones realizadas; b) modalidad de esas interdicciones; c) promedio de edad de las personas jurídicamente incapacitadas; d) motivo de las interdicciones. El análisis de los documentos apuntó que los mandados de inscripción del registro de interdicción no informan correctamente la motivación de la sentencia, lo que imposibilita establecer los motivos y los límites de la interdicción. Tal práctica alcanza la autonomía de la persona con deficiencia, pues el no conocimiento público de la naturaleza de la deficiencia reduce su voluntad para demás actos en que estaría plenamente apta, violando el derecho a la inclusión de la persona con deficiencia.

PALABRAS CLAVE: Persona con deficiencia; Interdicción; Investigación empírica.

\section{INTRODUÇÃO}

A Convenção sobre os Direitos das Pessoas com Deficiência no seu artigo 12 reconhece que as pessoas com deficiência "gozam de capacidade legal em igualdade de condições com as demais pessoas em todos os aspectos da vida”. Ratificada pelo Congresso Nacional, por meio do decreto legislativo $\mathrm{n}^{\mathrm{0}} 186$, de 09 de julho de 2008, em conformidade com o previsto no $\S 3^{\circ}$ do art. $5^{\circ}$ da Constituição Federal de 1988, é o primeiro tratado internacional a ingressar no ordenamento jurídico brasileiro com o status de emenda constitucional.

O documento internacional tem como premissa uma abordagem social dos direitos das pessoas com deficiência. O novo modelo separa definitivamente questões "médico-patológicas" das deficiências, passando a entendê-las não como "desvantagem em decorrência de condições médicas", mas como uma incumbência à sociedade, responsável por encontrar um meio de superar a desigualdade, gerada pela 
própria organização social, de modo a oferecer à pessoa com deficiência condições de ser plenamente inserida em paridade com todas as outras pessoas. O escopo do paradigma adotado é a inclusão, entendida em sentido de plena participação social.

Dentro deste contexto, em âmbito interno, a lei 13.146, 06 de julho de 2015 - Lei Brasileira de Inclusão da Pessoa com Deficiência (LBI) - regulamentando a Convenção, alterou os dispositivos sobre capacidade civil do Código Civil de 2002, para dispor que o regime das incapacidades tem como única hipótese de incapacidade absoluta, ser a pessoa menor de 16 anos. Deslocando para incapacidade relativa, a hipótese de causa transitória ou permanente de não expressão de vontade e suprimindo a hipótese dos que por enfermidade ou deficiência mental não tiverem necessário discernimento para a prática dos atos civis.

As mudanças legislativas esbarram no desafio de aplicar o modelo igualitário, a uma sociedade acostumada a buscar na interdição o melhor meio de atender a pessoa com deficiência. Na realidade, a operatividade da convenção através da LBI promove a superação do conceito médico de deficiência, para superar também a prática de uma tutela meramente assistencialista.

$\mathrm{O}$ antigo modelo tinha por objetivo auxiliar a pessoa com deficiência, mas a enxergava como diferente e como alguém ser ajudado, sendo sua vontade irrelevante. É dentro dessa abordagem que se enquadra o instituto da interdição, no qual retira da pessoa a sua autonomia da vontade, transferindo-a para o curador, cabendo a ele as decisões sobre as escolhas, no todo ou em parte, da vida da pessoa interditada. Com o pretexto de assistir, permitia-se a exclusão, lógica contrária à normativa atual de inclusão.

$\mathrm{O}$ instituto da interdição, portanto, tende-se a colidir facilmente com os ditames da Convenção ${ }^{03}$.

A incongruência entre abordagem da questão na antiga redação dos artigos $3^{0}$ e $4^{0}$ do Código Civil e a reforma buscada pela atual redação dos dispositivos motivou a realização de pesquisa empírica descritiva-quantitativa que demonstre a realidade das interdições e se se configuram em barreira para a inclusão.

\footnotetext{
${ }^{03}$ A expectativa da doutrina é que o número de interdição diminua na medida em que ações efetivam de inclusão se realizem. Nesse sentido, afirmam Alencar, Assis e Musse: "[...] em tese, quanto maior a adesão à referida Convenção, maior o reconhecimento jurídico e social das pessoas com deficiência como atores sociais, dotados de autonomia [...]. Assim, menor o número de pessoas com deficiência submetidas a processos judiciais de interdição civil e à curatela" (ALENCAR, Cicero Pereira; ASSIS, Daniel Adolpho Daltin; MUSSE, Luciana Barbosa. Da interdição civil à tomada de decisão apoiada: uma transformação necessária ao reconhecimento da capacidade e dos direitos humanos da pessoa com deficiência. Revista de Estudos Empíricos em Direito, v. 3, n. 2, jul. 2016, p. 226-247).
} 
Para tanto, foi analisada a escrituração dos livros de registro desde a vigência do Código Civil de 2002 do $1^{\circ}$ Cartório de Registro Civil das Pessoas Naturais da cidade de Ribeirão Preto, Estado de São Paulo, para verificar o número de interdições ocorridas a partir da vigência do Código Civil de 2002, a fim de compreender: a) se a "cultura de interdição absoluta" efetivamente existiu no Brasil ao longo da vigência do Código Civil de 2002? Pois, ainda que de forma imprecisa, já continha norma para a modulação da incapacidade, como relativa, da pessoa com discernimento reduzido ou sem desenvolvimento mental completo ${ }^{04}$; b) se a modificação legislativa trazida pela LBI em 2015 impactou nas interdições, para respeitar a autonomia da pessoa, limitando ao mínimo possível a interferência na sua vontade.

$\mathrm{O}$ artigo apresenta arcabouço teórico-legal sobre o regime de incapacidades e confronta com os resultados obtidos nos livros do $1^{\circ}$ Cartório de Registro Civil das Pessoas Naturais de Ribeirão Preto para apontar se a alteração do paradigma legal se mostra efetiva.

\section{CAPACIDADE CIVIL E O REGIME DAS INCAPACIDADES}

O estudo da capacidade civil e o regime das incapacidades é tema próprio da parte geral do direito civil, pois interfere na validade dos atos jurídicos e se estende a outros ramos da ciência jurídica.

A capacidade civil compreende a capacidade de direito e a de fato. A capacidade de direito é a aquisição de direitos atribuída indistintamente a todas as pessoas. A capacidade de fato (agir ou de exercício) é a aptidão para exercer por si os atos da vida civil. Considera-se pessoa capaz aquela que coaduna as duas capacidades.

A capacidade de exercer direitos das pessoas jurídicas é sem limitação, enquanto as pessoas naturais poderão sofrer limitação em sua capacidade de fato sendo limitada de forma absoluta ou relativa pela lei.

A redação original do Código Civil de 2002 limitou a capacidade de fato em razão da idade (art. $3^{\circ}$, I e art. $4^{\circ}$, I), em razão de estado de saúde física ou mental, permanente ou temporária, mais grave ou menos grave (art. 3, II e III e art. $4^{\circ}$, II e III) e da prodigalidade (art. $\left.4^{\mathrm{o}}, \mathrm{IV}\right)$. A incapacidade em razão do estado de saúde física ou mental era limitada de forma absoluta no caso de pessoa com enfermidade

\footnotetext{
${ }^{04}$ A redação original (revogada pela LBI) dos incisos II e III do artigo $4^{\circ}$ do CC já estabelecia como relativamente incapaz a pessoa com deficiência mental que tivesse discernimento reduzido e o excepcional, sem desenvolvimento mental completo.
} 
ou deficiência mental não ter discernimento para a prática de atos civis ou quando a pessoa não pudesse exprimir sua vontade; e era limitada relativamente quando tivesse discernimento reduzido decorrente de alcoolismo, tóxico ou deficiência mental e ainda, na hipótese dos excepcionais sem desenvolvimento mental completo ${ }^{05}$.

A personalidade da pessoa não é alterada em razão da limitação da capacidade de fato (agir ou de exercício), uma vez que a criança, o adolescente ou a pessoa interditada civilmente conserva integralmente sua individualidade. A limitação da capacidade de fato dessas pessoas está no exercício de sua capacidade na vida jurídica, e para cada situação, se for limitada absoluta ou relativamente, haverá solução jurídica correspondente, de representação ou de assistência. A limitação da capacidade é sobre o exercício, sobre agir por sua conta nos atos da vida civil, não é restrição sobre a pessoa.

Para Pontes de Miranda, o critério para considerar a pessoa como plenamente capaz, relativamente ou absolutamente incapaz deveria ser o da eficiência de suas atividades na vida, entendia que as causas patológicas e/ou as manifestações exteriores embora visíveis, eram superficiais ${ }^{06}$. À primeira vista, o critério indicado por Pontes de Miranda da eficiência da atividade parece ter sido admitido pela redação original do Código Civil nos artigos $3^{\circ}$, II e $4^{\circ}$, II do CC de 2002 no uso das expressões "necessário discernimento" ou "discernimento reduzido".

Porém, antes do advento da LBI, o suprimento da incapacidade dos deficientes intelectuais que atingiam a idade da maioridade civil ocorria obrigatoriamente pela interdição, que tem a natureza de ser uma medida extrema e excepcional. Além disso, a obrigatoriedade da designação de um curador resulta, ao contrário do pretenso intuito de proteção, na limitação injustificada da capacidade civil e a autonomia do interdito.

O comportamento dos indivíduos frente a pessoas com deficiência é analisada por Lafayette Pozzoli ${ }^{07}$ que identifica três tipos de condutas: de indiferença, de

\footnotetext{
${ }^{05}$ Nota-se que as expressões "deficiência mental com discernimento reduzido" e "excepcional, sem desenvolvimento mental completo" são imprecisas. A designação apropriada parece ser a de "deficiência intelectual", já admitida pelo IBGE no Censo de 2010 e presente na lei 12.470/2011.

${ }^{06}$ MIRANDA, Pontes de. Tratado de Direito Privado: Parte Geral. Tomo I: Introdução, Pessoas Físicas e Jurídicas. Atualizado por: Judith Martins-Costa, Gustavo Haical e Jorge Cesa Ferreira da Silva. São Paulo: Revista dos Tribunais, 2012, p. 316.

${ }^{07}$ POZZOLI, Lafayette. Pessoa portadora de deficiência e cidadania. In: Defesa dos direitos das pessoas portadora de deficiência. Luiz Alberto David de Araújo (coord.). São Paulo: Revista dos Tribunais, 2006.
} 
caridade e paternalista ${ }^{08}$. Contudo, essas condutas não se restrigem à pessoa com deficiência, também são perceptíveis nas situações de limitação da capacidade de fato, especialmente a conduta paternalista.

A posição paternalista se destaca no campo jurídico. O regime da incapacidade pretende a proteção dessas pessoas por não serem dotadas de suficiente experiência para exercer, por si mesmas, os atos civis, porém essa proteção apenas é eficiente no tocante à segurança do patrimômio. Em relação aos interesses extrapatrimoniais deve-se observar o vetor constitucional do princípio da dignidade da pessoa humana para permitir que o incapaz civil tenha o direito de manifestar sua vontade sobre temas como saúde, educação, desejos e sonhos e que essa vontade seja considerada.

O ideal seria que em situações jurídicas existenciais que envolvam o próprio desenvolvimento humano do indivíduo, o regime das incapacidades seja repensado ${ }^{09}$ para que o incapaz civil tenha participação direta sobre as decisões basilares para sua formação como indivíduo.

A legislação atual reflete esse novo pensar a respeito da capacidade, incapacidades e interdição, pois houve uma significativa alteração sobre o tema na redação original do Código Civil de 2002 e avanço ainda maior na nova redação instituída pela LBI. No Código Civil atual as hipóteses de limitação da capacidade prevista nos art. $3^{\circ}$ e art. $4^{\circ}$ do Código Civil de 2002 são distintas das do Código Civil de 1916 que no tocante à incapacidade em razão de estado de saúde física ou mental não diferenciava uma situação de outra, considerando como absolutamente incapazes aqueles que se enquadrassem na denominação genérica de "loucos de todos os gêneros" (art. 5, II do CC/1916).

Dessa forma, exemplificando, até o ano de 2002, as pessoas com síndrome de Down, maiores de 18 anos, eram classificadas como "loucos de todos os gêneros", portanto, impossibilitadas de exercerem os atos da vida civil, devendo ser interditadas de forma absoluta. Dado comprovado em pesquisa realizada no ano de

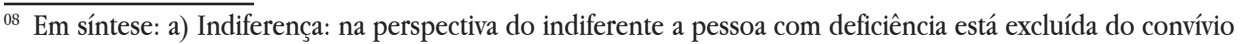
social, tratando-se de um processo de exclusão que significa negar à pessoa o susbtractum básico da cidadania que o 'direito de ter direitos'. Não é cidadão. b) Caridade: na perspectiva do caridoso a pessoa com deficiência é um objeto, não se enquadra no conceito jurídico de 'pessoa', não é sequer sujeito de direitos. c) Paternalista: para o partenalista a pessoa com deficiência não está capacitada para exercer seus direito, é absolutamente incapaz (Ibidem, p. 191/192)

${ }^{09}$ Nesse sentido, escreveu STANZIONE, Pasquale. Personalità, capacità e situazioni giuridiche del minore. Revista Trimestral de Direito Civil. Rio de Janeiro: Renovar, n. 1, jan/mar. 2000, p. 113-122 e RODRIGUES, Rafael Garcia. A pessoa e o ser humano no novo Código Civil. In: A parte geral do novo Código Civil: estudos na perspectiva civil-constitucional. Gustavo Tepedino (coor.). Rio de Janeiro: Renovar, 2002, p. 1-34. 
2001, quando se demonstrou que 99,32\% das interdições na cidade de São Paulo ocorriam de forma tota ${ }^{10}$, ou seja, a pessoa interditada era considerada absolutamente incapaz.

A partir da vigência do Código Civil até a alteração trazida pela LBI, pessoas com deficiência intelectual deveriam ser interditadas de forma relativa, dada a letra da lei de "deficiência mental com discernimento reduzido" e "excepcional, sem desenvolvimento mental completo".

Já a redação atual, com a vigência da LBI, a única hipótese de incapacidade absoluta é em razão da idade, ou seja, para a pessoa menor de 16 anos. As hipóteses de limitação relativa decorreram da idade, menor de 18 anos, de vício em álcool ou tóxico, por prodigalidade e na impossibilidade de exprimir a própria vontade. A limitação da capacidade decorrente de deficiência mental ou intelectual foi revogada pela lei.

\section{O MÉTODO DE CONSULTA AOS REGISTROS DE INTERDIÇÃO}

A regra geral da capacidade civil é que ao completar a maioridade a pessoa natural adquire capacidade plena, de gozo e de direitos, para os atos da vida civil. Porém, se ao completar os 18 anos houver a incidência de uma das hipóteses dos incisos II a IV do artigo $4^{\circ}$ do Código Civil, ela deverá ser interditada judicialmente para que seja declarada sua incapacidade relativa e designado um curador. Por determinação da Lei de Registros Públicos (lei 6.015, de 31 de dezembro de 1973) nos artigos 89 e 92, todas as interdições da comarca devem ser registradas no cartório do primeiro ofício.

Por isso, a pesquisa empírica realizada ocorreu no município de Ribeirão Preto, Estado de São Paulo, junto ao $1^{\circ}$ Cartório de Registro Civil. O levantamento dos dados da pesquisa teve como marco inicial a vigência do Código Civil de 2002, que ocorreu em janeiro de 2003 e como termo final os registros disponíveis para consulta até julho de 2017.

$\mathrm{Na}$ realização da pesquisa foram analisados 14 livros de registro, cada um

${ }^{10}$ Pesquisa realizada por VIEIRA, Patrícia Ruy. Estudo de prevalência dos Transtornos psiquiátricos na determinação da interdição civil no município de São Paulo. Dissertação de Mestrado, São Paulo, Unifesp, 2003.. 
com 300 folhas, que correspondem a 600 páginas ${ }^{11}$, referentes a atos de novembro de 2002 a julho de 2016. Cumpre esclarecer que não se confunde o período da pesquisa com o registro dos atos, pois os dados da pesquisa são levantados em livros arquivados; o livro corrente, não completo, não pôde ser objeto de pesquisa porque está sendo utilizado pelo cartório ${ }^{12}$.

O registro das interdições da comarca deve ser escriturado no livro " $E$ " juntamente com os registros de emancipação, inscrições de aquisição de nacionalidade, inscrição de sentença de divórcio quando o casamento for registrado em outra comarca, inscrições de casamento no estrangeiro, registros de ausência e registros de morte presumida.

Dos 14 livros analisados foram encontrados 3.034 registros de interdição, o que representa aproximadamente $37 \%$ dos atos registrados nos livros "E". Tal dado chama a atenção porque o livro "E" escritura outras espécies de atos, como mencionado acima, e ainda assim, aproximadamente quatro em cada dez escrituraçóes correspondem ao procedimento de interdição.

Cada registro de interdição foi analisado conforme formulário padronizado de levantamento de dados criado com o intuito de verificar: a) quantidade de interdição por incapacidade absoluta e por incapacidade relativa; b) idade dos interditados; c) motivo das interdições.

Dos 3.034 registros analisados, respondendo ao item " $\mathrm{a}$ ", foram encontradas 2.861 interdições por incapacidade absoluta, que representa 94,3\% do total, e 173 por incapacidade relativa, representando somente $5,70 \%$.

Com o item "b", a pesquisa buscou constatar a possibilidade de relacionar a interdição com a idade do interdito, para, por exemplo, verificar se uma faixa etária está mais sujeita a interdição.

Na resposta do item "c" sobre os motivos da interdição, descobriu-se que os mandados de inscrição do registro não informam a motivação da sentença. Tanto antes como durante a vigência da LBI, essa ausência ou imprecisão acarreta dificuldade

\footnotetext{
${ }^{11}$ Segundo a lei de registros públicos, artigo 33, os livros dos cartórios de registro de pessoas naturais contêm todos 300 folhas, com exceção do livro E. O parágrafo único prevê que: "no Cartório do $1^{\circ}$ Ofício ou da $1^{\text {a }}$ Subdivisão judiciária, em cada comarca, haverá outro livro para inscrição dos demais atos relativos ao estado civil, designado sob a letra "E", com cento e cinquenta (150) folhas, podendo o Juiz competente, nas comarcas de grande movimento, autorizar o seu desdobramento pela natureza dos atos que nele devam ser registrados, em livros especiais". Todavia, observou-se que, na prática, esses livros também possuíam 300 folhas (600 páginas).

${ }^{12}$ A organização do cartório ocorre conforme as normativas de encerramento e arquivo dos artigos $3^{\circ}, 24$ e 26 da Lei de Registros Públicos. Justamente por isso, foi possível a consulta dos registros arquivados, sempre efetuada dentro do próprio cartório.
} 
em estabelecer a causa da interdição $0^{13}$ e o mesmo acontece em relação aos limites, nos casos da interdição relativa.

\subsection{OS GRUPOS DE CLASSIFICAÇÃO DAS INTERDIÇÕES}

A pesquisa abrange período com duas redações distintas dos artigos $3^{\circ} \mathrm{e}$ $4^{\mathrm{O}}$ do Código Civil, por isso, para melhor compreensão dos dados levantados no cartório, é primordial a verificação do texto legal antes e depois da alteração. Assim, a letra da lei vigente até 2015 , ou seja, antes da LBI era

Art. 3o São absolutamente incapazes de exercer pessoalmente os atos da vida civil:

I - os menores de dezesseis anos;

II - os que, por enfermidade ou deficiência mental, não tiverem o necessário discernimento para a prática desses atos; III - os que, mesmo por causa transitória, não puderem exprimir sua vontade.

Art. $4^{0}$ São incapazes, relativamente a certos atos, ou à maneira de os exercer:

I - os maiores de dezesseis e menores de dezoito anos;

II - os ébrios habituais, os viciados em tóxico, e os que, por deficiência mental, tenham o discernimento reduzido; III - os excepcionais, sem desenvolvimento mental completo; IV - os pródigos.

(Destaque em itálico nosso: indicam o texto legal alterado ou revogado).

Com a entrada em vigência da LBI, o texto legal passou a ser

Art. $3^{\circ}$ São absolutamente incapazes de exercer pessoalmente os atos da vida civil os menores de 16 (dezesseis) anos.

Art. $4^{\underline{0}}$ São incapazes, relativamente a certos atos ou à maneira de os exercer:

I - os maiores de dezesseis e menores de dezoito anos;

${ }_{13}$ O mesmo problema já fora acenado por Patrícia Vieira em pesquisa semelhante: "os estudos realizados e a jurisprudência pátria apontam algumas falhas do procedimento [de interdição] identificáveis com maior facilidade: [...] o registro de sentença sem expressa menção da causa de interdição" (VIEIRA, Patrícia Ruy. A interdição civil no direito brasileiro. Revista dos Tribunais, v.93, n.826, ago. 2004, p. 114). 
II - os ébrios habituais e os viciados em tóxico

III - aqueles que, por causa transitória ou permanente, não puderem exprimir sua vontade;

IV - os pródigos.

Para verificação de eventual interdição de pessoa com deficiência, considerou-se que como na redação atual da LBI só caberá a relativa e como na prática cartorial vigente na redação anterior quando da incapacidade absoluta não havia indicação da causa, buscou-se restringir a análise aos 173 casos de incapacidade relativa, sendo que somente 12 ocorreram após a vigência da LBI.

Os 173 casos foram classificados em cinco grupos, sendo que cada registro em um único grupo.

$1^{0}$ grupo: Registros que, expressamente, indicam os incisos que motivaram a interdição

Os casos do $1^{\circ}$ grupo representaram 6,4\% dos registros de interdição relativa (11 de 173) e todos ocorreram antes da vigência da LBI. Dos 11 casos nessa categoria, dez indicaram o inciso II do Código Civil e um apontou como fundamento "o inciso II ou III do Código", não houve nenhum registro que discriminasse o inciso IV.

A indicação do inciso II nos registros antes da vigência demonstra que as dez interdições tiveram, necessariamente, como motivo ensejador da mesma uma das seguintes causas: a) embriaguez habitual; b) toxicomania; ou c) deficiência mental.

$2^{\circ}$ grupo: Registros que impõem limitação de "tomar decisões relativas ao tratamento de saúde" ou "celebrar contratos, inclusive de trabalbo" ou ambos ao mesmo tempo.

Tais registros foram todos realizados antes da vigência da LBI e, por isso, infere-se que encontram como fundamento legal da interdição os incisos II e III do artigo $4^{\circ}$, pois a hipótese do inciso IV, referente à interdição por prodigalidade já era, conforme determinação do artigo 1.782 do diploma civil, limitada a atos patrimoniais.

Nesse grupo foram classificados 40 registros dos 173 , o equivalente a $23,1 \%$. 
Não é possível precisar quantos destes tratam de pessoa com deficiência, mas aponta-se que a limitação imposta de não "tomar decisões relativas ao tratamento de saúde" ou de não "celebrar contratos, inclusive de trabalbo" passou a ser proibida pela $\mathrm{LBI}^{14}$.

$3^{0}$ grupo: Registros em que constam expressamente a limitação de atos negociais a que se refere o artigo 1.782 do Código Civil

Pela dicção do artigo 1.772 antes das alterações promovidas pela LBIe por sua revogação pelo Código de Processo Civil, deviam-se constar expressamente os limites da interdição apenas nos casos de deficiência mental, alcoolismo e toxicomania e nos casos em que o desenvolvimento mental não fosse completo. Em tais hipóteses, as restrições da medida poderiam circunscrever-se àquelas do artigo 1.782.

Com o advento da LBI, o artigo foi alterado: passou-se a utilizar o artigo 1.782 sobre a incapacidade do pródigo como limite máximo e não mais possível à fixação das restrições em todos os casos de curatela, como proclama o artigo 85 da nova lei. Ainda, os registros que explicitam o artigo 1.782 como parâmetro da limitação da capacidade negocial dos interditados, certamente não incluem os pródigos tendo em vista que sua incapacidade já é, obrigatoriamente, aquela do artigo $1.782^{15}$.

O $3^{\circ}$ grupo compreende 45 dos 173 registros (26\%), sendo 11 deles após a vigência da LBI o que indica outro ponto relevante: em 11 dos 12 casos de interdição após a mudança legislativa, foi aplicada a maior restrição possível da capacidade, ou seja, o impedimento a todos os atos de natureza patrimonial que não se limitem à mera administração.

$4^{\mathbf{0}}$ grupo: Os interditados por prodigalidade (Art. $4^{0}$, inciso IV)

Por exclusão, admite-se que são interditados por prodigalidade (Art. $4^{\mathrm{o}}$, in-

\footnotetext{
${ }_{14}$ Art. 85 da LBI. "A curatela afetará tão somente os atos relacionados aos direitos de natureza patrimonial e negocial. § $1^{\circ}$ A definição da curatela não alcança o direito ao próprio corpo, à sexualidade, ao matrimônio, à privacidade, à educação, à saúde, ao trabalho e ao voto."

${ }^{15}$ É preciso esclarecer o atropelo legislativo realizado entre o Código de Processo Civil e a Lei Brasileira de Inclusão. Mesmo que formalmente o Código de Processo Civil tenha ab-rogado o artigo 1.782 do Código Civil, a nova redação do mesmo na LBI implica sua inserção no campo normativo e, por isso, deve o mesmo ser respeitado. Segue-se a opinião de Fredie Didier Jr., que não pode o CPC "revogar o que não estava previsto" (DIDIER JR., Fredie. Estatuto da Pessoa com Deficiência, Código de Processo Civil de 2015 e Código Civil: uma primeira reflexão. 2015).
} 
ciso IV) aqueles com limitação exclusiva a atos patrimoniais e que o registro não remetia a alguma causa para tal medida das restrições, quase numa direção de raciocínio inversa ao do $3^{\circ}$ grupo. Tais registros de interdição são sucintos na medida em que apenas têm a função de impedir o indivíduo de realizar atos negociais, expressão ampla, que encontra melhor definição no artigo 1.782 do Código Civil. Enquadram-se nessa categoria 41 dos 173 relativamente incapazes $(23,7 \%)$.

Depois das mudanças propostas em 2015, tal tipo de inscrição poderia incluir também outros casos de interdição, tendo em vista a curatela como instrumento exclusivamente patrimonial. Todavia, nenhuma das 12 interdições realizadas na vigência da LBI havia disposição no registro adequada a este grupo.

$5^{\circ}$ grupo: Registros demasiadamente genéricos tornando difícil especifcar qualquer motivo para a interdição.

Nesse grupo foram encontrados 36 dos 173 registros, ou seja, 20,8\% das interdições relativas ocorreram nesses moldes, sendo que uma após a LBI.

Os registros desta categoria estabelecem para o curador a função de auxiliar o interdito na "regência de sua pessoa e seus bens" sem especificar os limites da interdição. $\mathrm{O}$ ato de prever a regência das pessoas faz crer que os atos de natureza pessoal (voto, casamento, contrato de trabalho, tratamento de saúde) também estejam sujeitos ao controle do curador. A categoria, portanto, é a mais temerária, abrindo espaço para um controle exagerado do curador e que, na prática, dificulta $o$ conhecimento, por parte de terceiros, dos limites efetivos da curatela.

\section{RESULTADOS}

Os dados obtidos nos 3.034 registros de interdição na comarca de Ribeirão Preto, embora represente na maioria uma realidade de pré-vigência da LBI, informam que apenas 173 registros se referem à interdição por incapacidade relativa; os outros 2.861 tratam de interdição absoluta. Do total desses registros, apenas 12 ocorreram após a vigência da LBI e na modalidade de interdição relativa.

A discrepante prevalência da interdição absoluta fica evidente no GRAF. 1. Título do gráfico: Quantidade de interditados e grupos de divisão dos relativamente incapazes. 


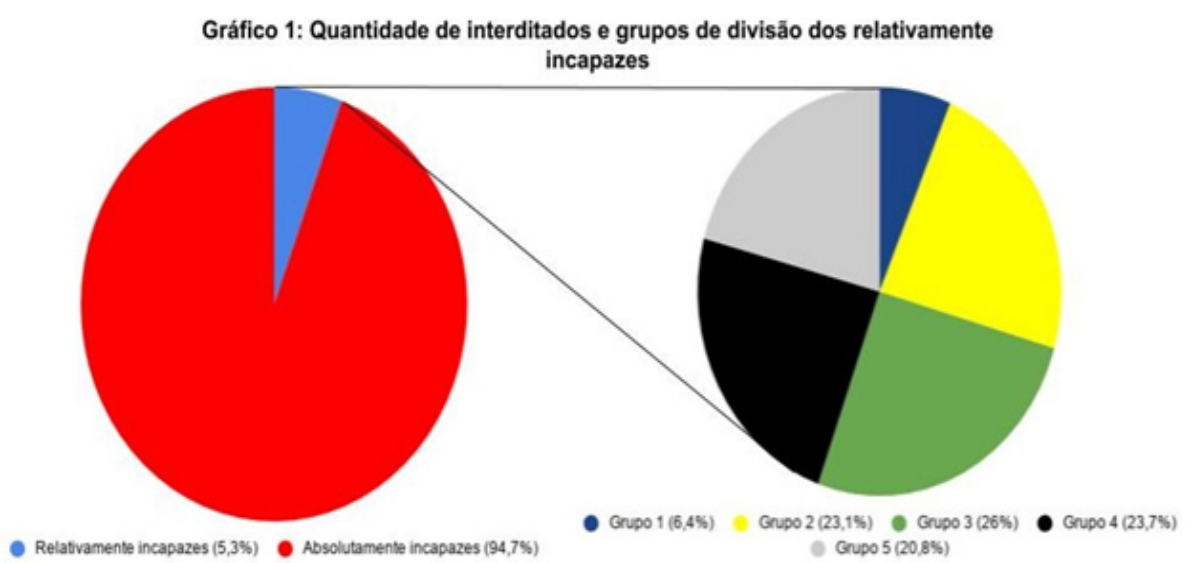

Fonte: Elaborado pelos autores.

Assim, dos 173 casos de interdição relativa, temos que 161 ocorreram antes da vigência da LBI. Desse montante (161), excluindo os referentes ao Grupo 4 (prodigalidade) e ao Grupo 5 (registros de interdição genérica), pode-se dizer que 84 casos de interdição tiveram por motivação uma das três hipóteses: embriaguez habitual, toxicomania, ou deficiência mental. Entretanto, como os registros de interdição são documentos sucintos que não explicitam os motivos da interdição, não é possível apontar quantas pessoas com deficiência foram interditadas nesta modalidade.

Por outro lado, os 84 registros representam uma pequena quantidade quando comparados aos 2.861 registros de interdição por incapacidade absoluta ocorrida antes da LBI que, obrigatoriamente, tinham como motivação enfermidade ou deficiência mental ou impossibilidade de expressão da vontade (artigo $3^{\circ}$, incisos II e III do texto anterior do CC). No que tange a esses registros de incapacidade absoluta, devida à ausência clara de motivação ${ }^{16}$, não se pode precisar o número exato de interdições de pessoa com deficiência.

Sobre os dados obtidos no Grupo 1 (indicam os incisos que motivaram a interdição), chama atenção o número irrisório de interdições relativas em que se o fundamento legal é apontado, e mais curioso ainda é verificar que mesmo indicando o fundamento não é possível conhecer a causa da interdição, se por dependência de álcool ou substância química ou por deficiência mental. Após a vigência da LBI, não houve interdição classificada neste grupo.

Quanto aos dados do Grupo 2 (impõe limitação de decisões sobre tra-

${ }_{16}$ Os registros de incapacidade absoluta se assemelham aos registros do Grupo 5 dos casos de incapacidade relativa. 
tamento de saúde ou celebração de contratos), a extensão da curatela a atos não patrimoniais e negociais violam o artigo $85 \mathrm{da} \mathrm{LBI}$, pois o trabalho e a saúde são direitos sociais previstos constitucionalmente (art. $6^{\circ} \mathrm{da} C F$ ), por isso são considerados fundamentais, relativos à esfera pessoal, devendo distanciar-se de lógica patrimonial, não obstante a tutela da saúde e as relações de trabalho implicar reflexos econômicos. Após a vigência da LBI, não houve interdição classificada neste grupo, o que se considerou positivo, uma vez que está em conformidade com o novo regime de incapacidades.

No Grupo 03 (limitação restrita a atos negociais) encontram-se 11dos 12 registros de interdição após a LBI, indicando a aplicação da lei para que a curatela se limite aos atos negociais. O único caso após a LBI que não consta deste grupo foi classificado no Grupo 5 (de interdição genérica).

\subsection{A IDADE DOS INTERDITADOS E EVENTUAIS IMPLICAÇÕES}

A pesquisa referente à idade dos interditos refutou de modo parcial a hipótese inicialmente levantada de que haveria uma relação entre o número de interdições e o avanço da idade dos indivíduos, pois em relação aos interditados relativamente, a média de idade é 45 anos, sendo que a pessoa mais jovem foi interditada aos 18 anos e a mais velha aos 95 anos.

Os GRAF. 2 e 3 demonstram os dados obtidos em relação à idade dos interditados relativamente.

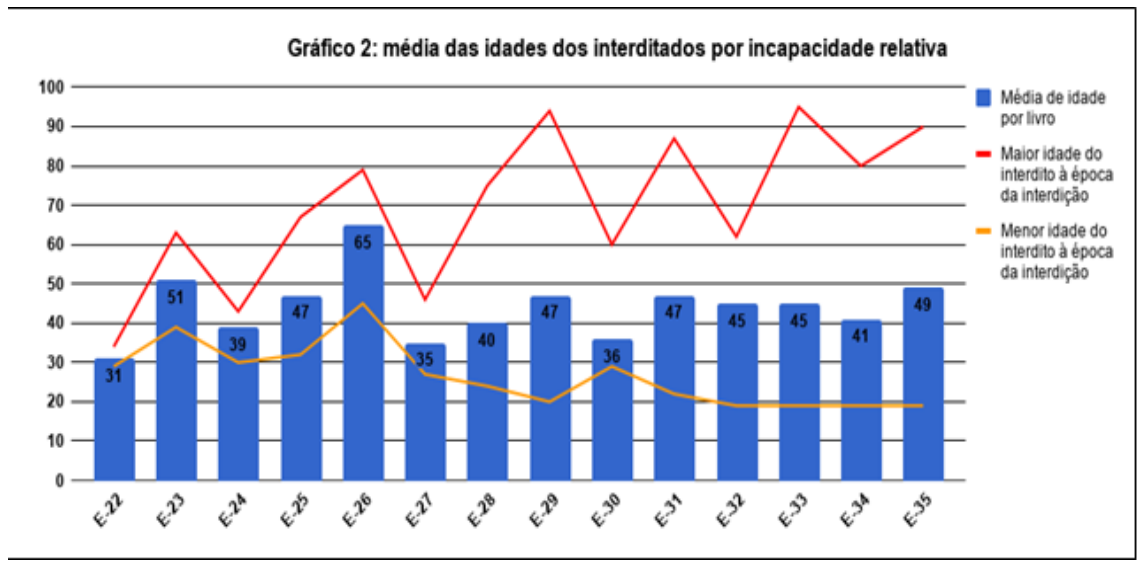

Fonte: Elaborado pelos autores. 


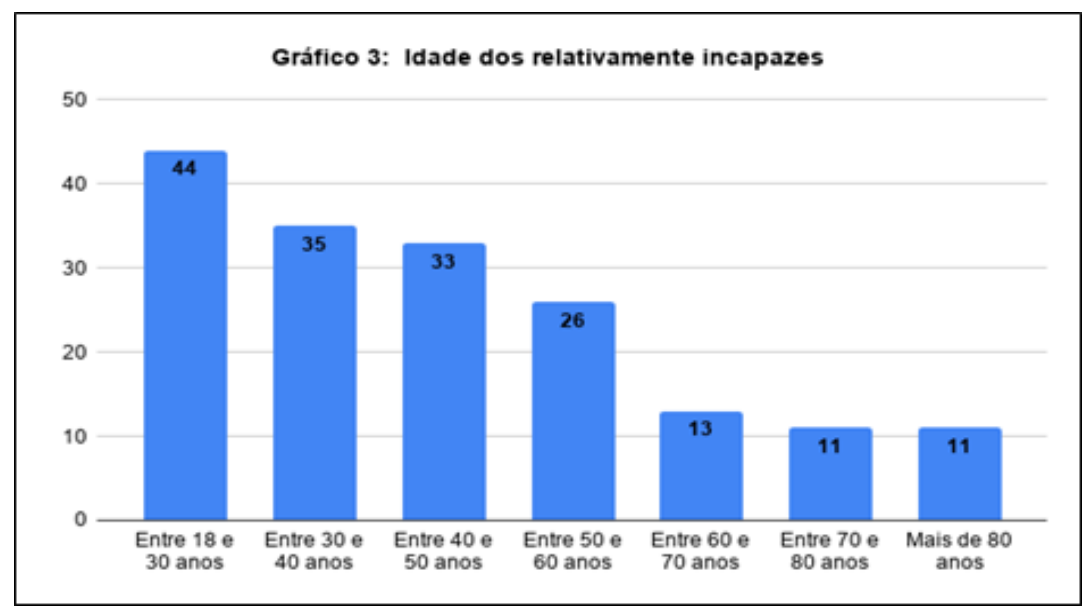

Fonte: Elaborado pelos autores

Os dados coletados permitiram aferir que a maior parte dos indivíduos é interditada ainda jovem, entre os 18 a 30 anos, embora o número de interditos por faixa etária mantenha-se elevado dos 18 aos 60 anos.

\section{CONCLUSÃO}

Antes da LBI era possível a interdição de forma absoluta ou relativa. A falta de clareza dos motivos da interdição nos mandados de inscrição remetidos ao cartório incumbido de registrá-las impede saber com precisão por esse meio como a pessoa com deficiência intelectual ou mental era interditada. Todavia, é possível inferir que a interdição absoluta era a regra para tais pessoas, pois, na comarca de Ribeirão Preto, para cada pessoa interditada de forma relativa, aproximadamente 49 foram interditados de forma absoluta, nos moldes dos incisos revogados II e III do artigo $3^{\circ}$ do CC, que determinavam como absolutamente incapazes as pessoas com enfermidade ou deficiência mental.

A LBI opera uma reforma no regime de incapacidades que, formalmente, é respeitada, uma vez que, as 12 interdições na vigência da lei foram todas por incapacidade relativa, sendo que 11 registros indicaram doenças, ou sequelas destas, como causa ensejadora da interdição e nestes casos foi prevista, como limite, à ação do curador os atos previstos no artigo 1.782 do Código Civil, em respeito ao artigo 85 da LBI.

Entretanto, substancialmente, ainda permanecem problemas: a) a padro- 
nização dos limites da interdição e dos poderes do curador; b) a motivação das interdições não permite uma interpretação segura de que o conceito social de deficiência, previsto pela Convenção sobre os Direitos das Pessoas com Deficiência, seja efetivamente aquele adotado; c) o desaparecimento repentino dos registros de interdição absoluta que antes representava 94,3\% dos casos.

Em todos os registros após a LBI, a disposição relativa à limitação dos atos do interditado é a mesma: "ficando impedido de sozinho, nos termos do art 1.772 caput e 1.782 do Código Civil emprestar, transigir, dar quitação, alienar, hipotecar, demandar ou ser demandado, receber ou celebrar contratos em geral, sem estar assistido por [...]". A disposição, enquanto se apoia sempre integralmente ao artigo 1.782 do Código, é genérica e contraria o artigo 12 da Convenção Internacional ${ }^{17} \mathrm{e}$ o artigo 84 da $\mathrm{LBI}^{18}$.

Sobre o segundo problema, os 11 registros mais detalhados mencionaram sempre uma condição médica dos interditados, todavia, não é possível saber se o fundamento de interdição foi a efetiva impossibilidade de manifestação da vontade advinda dessa condição (o que seria a aplicação correta do artigo $4^{\circ}$ do Código Civil) ou se são pessoas com deficiência que, embora possam manifestar sua vontade, foram interditados para obstrução de sua participação plena em razão das barreiras sociais existentes.

As considerações sobre os dois primeiros problemas ajudam, em parte, a analisar o terceiro ponto controverso, ou seja, o desaparecimento da interdição absoluta e sua efetiva relevância. Considerando os dados anteriores à vigência da LBI, se confirma a hipótese inicial da existência de uma "cultura da interdição absoluta" que não foi alterada com a mudança formal da lei. O que acontece, na realidade, é a transformação da interdição relativa padronizada, limitante de todos os atos patrimoniais, como novo parâmetro comparável à antiga interdição absoluta. Em outras palavras, na ausência de interdição absoluta pede-se, e obtém-se, a interdição relativa a todos os atos patrimoniais sem se considerar a efetiva capacidade de cada interditando.

\footnotetext{
${ }^{17}$ Diz o parágrafo $4^{\circ}$ do artigo 12: Os Estados Partes assegurarão que todas as medidas relativas ao exercício da capacidade legal incluam salvaguardas [...]. Essas salvaguardas assegurarão que as medidas relativas ao exercício da capacidade legal [...], sejam proporcionais e apropriadas às circunstâncias da pessoa, se apliquem pelo período mais curto possível e sejam submetidas à revisão regular [...].

${ }^{18}$ Art. 84. A pessoa com deficiência tem assegurado o direito ao exercício de sua capacidade legal em igualdade de condições com as demais pessoas. [...] $\S 3^{\circ}$ A definição de curatela de pessoa com deficiência constitui medida protetiva extraordinária, proporcional às necessidades e às circunstâncias de cada caso, e durará o menor tempo possível.
} 
Assim, a Convenção e a LBI promovem modificação relevante no ordenamento, mas não atingem plenamente seu objetivo. A vitória da alteração do texto normativo foi, de fato, excluir os atos pessoais da esfera de intervenção de um curador, entretanto, não se atingiu outro objetivo que é tornar a interdição instrumento secundário, que respeite a autonomia do indivíduo acima de tudo e buscar soluções alternativas, tais como a tomada de decisão apoiada.

De fato, o problema é a ainda incompleta assimilação do conceito de deficiência introduzido pela nova lei, assomam-se às questões supracitadas o fato de que na legislação brasileira convivem termos diversos para se referir ao mesmo conjunto social, reflexo de uma política legislativa, presa pelo tempo em que foi feita e que se torna elemento complicador pela falta de atualização terminológica legislativa (Alencar, Assis \& Musse, 2016, p.232). Essa é também uma das preocupações da Organização das Nações Unidas (ONU) para com o enfrentamento da questão pelo Brasil que recomenda ao país modificar toda disposição de lei que potencialmente possa reduzir a autonomia do indivíduo em algum aspecto ${ }^{19}$.

Se uma das metas propostas pela Organização das Nações Unidas é o pleno cumprimento do artigo 12, requer-se, portanto, uma revisão do atual procedimento de interdição e de seus reflexos no registro de interdição. Faz-se indispensável o acompanhamento da aplicação material das novas disposições legais que deve prosseguir além dos dados coletados nesta pesquisa.

Deve-se buscar fomentar o debate e a consciência a respeito da nova lógica legal no judiciário, bem como alterar a forma de atuação dos órgãos de registro para uma escrituração mais detalhada, com a exposição do exato motivo de interdição da pessoa, visto que a motivação genérica das decisões de interdição se torna em barreira para a inclusão, pois transforma a restrição ou a limitação em determinado campo em proscrição da vontade da pessoa com deficiência em todos os aspectos da vida.

A escrituração detalhada poderá servir como instrumento mais eficaz de controle à atividade jurisdicional na aplicação da LBI.

\footnotetext{
19 "A comissão insta ao Estado-parte a retirar todas as previsões legais que perpetuem o sistema de tomada de decisão substituída pela de um terceiro. A mesma também recomenda, que em consulta com organizações representativas de pessoas com deficiência e outras entidades, o Estado realize medidas concretas para substituir referido sistema por um outro que incentive a inteira autonomia, vontades e preferências das pessoas com deficiência, em plena conformidade com o artigo 12 da Convenção" UN Committee on the Rights of Persons with Disabilities (CRPD), Concluding observations on the initial report of Brazil, 4 September 2015, CRPD/C/ BRA/CO/1, p. 04 .
} 


\section{REFERÊNCIAS}

ALGUACIL, Maria José García. Protección jurídica de las personas con discapacidad. Madrid: Reus, 2016.

ALENCAR, Cicero Pereira; ASSIS, Daniel Adolpho Daltin; MUSSE, Luciana Barbosa. Da interdição civil à tomada de decisão apoiada: uma transformação necessária ao reconhecimento da capacidade e dos direitos humanos da pessoa com deficiência. Revista de Estudos Empíricos em Direito, v. 3, n. 2, p. 226-247, jul. 2016.

BRASIL. Decreto $n^{0}$ 6.949, de 25 de agosto de 2009. Promulga a Convenção Internacional sobre os Direitos das Pessoas com Deficiência e seu Protocolo Facultativo, assinados em Nova York, em 30 de março de 2007. Disponível em: http://www.planalto.gov.br/ccivil_03/_ato2007-2010/2009/decreto/d6949.htm. Acesso em: 25 ago. 2018.

BRASIL. Lei $\mathrm{n}^{0}$ 6.015, de 31 de dezembro de 1973. Dispões sobre os registros públicos, e dá outras providências. Disponível em: http://www.planalto.gov.br/CCivil_03/leis/L6015compilada.htm. Acesso em: 25 ago. 2018.

BRASIL. Lei $\mathrm{n}^{\mathbf{0}} \mathbf{1 0 . 4 0 6}$, de 10 de janeiro de 2002. Institui o Código Civil. Disponível em: http://www.planalto.gov.br/ccivil_03/leis/2002/L10406.htm. Acesso em: 25 ago. 2018.

BRASIL. Lei $\mathrm{n}^{\mathrm{0}}$ 13.146, de 06 de julho de 2015. Institui a Lei Brasileira de Inclusão da Pessoa com Deficiência (Estatuto da Pessoa com Deficiência). Disponível em: http://www.planalto.gov.br/ccivil_03/_ato2015-2018/2015/lei/113146.htm. Acesso em: 25 ago. 2018.

DIDIER JR. Fredie. Estatuto da Pessoa com Deficiência, Código de Processo Civil de 2015 e Código Civil: uma primeira reflexão. 2015. Disponível em: http:// www.frediedidier.com.br/editorial/editorial-187/. Acesso em 20 ago. 2018.

MIRANDA, Pontes de. Tratado de Direito Privado: Parte Geral. Tomo I: Introdução, Pessoas Físicas e Jurídicas. Atualizado por: Judith Martins-Costa, Gustavo Haical e Jorge Cesa Ferreira da Silva. São Paulo: Revista dos Tribunais, 2012.

POZZOLI, Lafayette. Pessoa portadora de deficiência e cidadania. In: Defesa dos direitos das pessoas portadora de deficiência. Luiz Alberto David de Araújo 
(coord.). São Paulo: Revista dos Tribunais, 2006.

RODRIGUES, Rafael Garcia. A pessoa e o ser humano no novo Código Civil. In: A parte geral do novo Código Civil: estudos na perspectiva civil-constitucional. Gustavo Tepedino (coord.). Rio de Janeiro: Renovar, 2002. p. 1-34.

STANZIONE, Pasquale. Personalità, capacità e situazioni giuridiche del minore. Revista Trimestral de Direito Civil. Rio de Janeiro, Renovar, n. 1, p. 113-122, jan/mar. 2000.

SCORRETTI, Carlo. Un mondo che cambia: come valutare oggi la disabilità. Rivista italiana di medicina legale. Milano: Giuffrè, v. 3, p. 551-570, 2010.

UNITED NATIONS. Committee on the Rights of Persons with Disabilities (CRPD). Concluding observations on the initial report of Brazil. 4 set. 2015. Disponível em: https://www.refworld.org/docid/55eed4d84.html. Acesso: 13 fev. 2019.

VIEIRA, Patrícia Ruy. A interdição civil no direito brasileiro. Revista dos Tribunais, v. 93, n. 826, p. 93-116, ago. 2004.

VIEIRA, Patrícia Ruy. Estudo de prevalência dos Transtornos psiquiátricos na determinação da interdição civil no município de São Paulo. Dissertação (Mestrado) - Unifesp, São Paulo, 2003.

Recebido em: 06/10/2018

Aceito em: 02/08/2019 